\title{
Budget Impact Analysis of the Introduction of Rituximab and Trastuzumab Intravenous Biosimilars to EU-5 Markets
}

\author{
Minyoung Jang ${ }^{1} \cdot$ Steven Simoens ${ }^{2}\left[\right.$ ] Taeksang Kwon $^{1}[\mathbb{C}$
}

Accepted: 30 November 2020 / Published online: 24 December 2020

(c) The Author(s) 2020

\begin{abstract}
Background Biologic treatments impose a large financial burden on healthcare payers. Subcutaneous formulations of trastuzumab and rituximab offer administration cost savings relative to the intravenous products through reduced preparation and infusion times. However, intravenous biosimilars have the potential to offset administration costs through lower drug costs. Objective The objective was to develop a budget impact model (BIM) from a payer's perspective for the EU-5 countries (UK, France, Germany, Spain, Italy) to demonstrate the economic impact of using intravenous trastuzumab and rituximab biosimilars. Methods An incidence-based BIM was developed to estimate the net budget impact utilising epidemiology data from the literature, market research data on the use of relevant treatments in all approved indications, and corresponding costs. The budget impact was estimated for 5 years following introduction of the biosimilars.

Results Analysis using the base-case results indicated that adoption of the biosimilars trastuzumab and rituximab would result in net cost savings. At year 5, the net budget saving ranged from $€ 4.05$ million to 303.86 million for rituximab and from $€ 19$ million to 172 million for trastuzumab. The cost saving could potentially extend treatment to $291-15,671$ more patients with rituximab and 622-3688 more patients with trastuzumab.

Conclusion This budget impact analysis emphasised that increased use of intravenous rituximab and trastuzumab biosimilars may result in cost savings from the payer's perspective across the EU-5 countries.
\end{abstract}

\section{Key Points}

This study revealed that introducing the intravenous biosimilars Herzuma and Truxima into the market where originators market both subcutaneous and intravenous formulations would reduce healthcare expenditure from the payer's perspective.

With the potential cost savings with use of the biosimilars, additional services could be utilized, and more patients could have access to biological drugs.

Supplementary Information The online version contains supplementary material available at https://doi.org/10.1007/s4025 9-020-00461-8.

Taeksang Kwon

Taeksang.Kwon@celltrionhc.com

1 Celltrion Healthcare, 19, Academy-ro 51, Yeonsu-gu, Incheon, South Korea

2 Department of Pharmaceutical and Pharmacological Sciences, KU Leuven, Leuven, Belgium

\section{Introduction}

Almost one-fifth of Europe's total population is aged $>65$ years, and the need for medical attention is on the rise, with increasing cases of cancer, autoimmune, and other diseases related to lifestyle [1-3]. Biologic treatments have reformed the management of many of these diseases. However, these drugs impose a huge financial burden on a country's healthcare budget [4], and the biologic share of total drug spend has gradually increased since 2014 [5]. In Europe, $29.9 \%$ of total drug spend in 2018 was attributed to biologics [5]. The leading speciality drugs contributing $60 \%$ of total growth of drug spend from year 2019 to 2023 are those used in oncology, autoimmune conditions, and immunology. New product launches of anti-cancer medications will also contribute to drug spending increases as oncology products are expected to have median prices well above \$US100,000 per year. As a result of increased prices for innovative cancer medicines, society will experience significant burdens when prioritizing area of treatment and allocating resources effectively to achieve the best health outcomes. Biosimilars, which are molecularly similar to the reference biologics, offer similar efficacy and safety. Biosimilars 
are often offered at a lower cost than the reference drug, thereby reducing the per-patient treatment cost and creating the possibility of increasing access among patients [6, 7]. One explanation for the lower cost of biosimilars is that the manufacturer avoids the lengthy and expensive route of larger trials in the process of drug approval. Furthermore, the availability of biosimilars may increase price competition and trigger discounts in the price of reference products, whilst the broader manufacturing base also increases supply. For example, an approximately $30-40 \%$ decrease in the cost price of the infliximab reference was reported following the introduction of biosimilars in most European countries [8]. The UK National Health Service (NHS) announced that the adalimumab biosimilar would save about $£ 300$ million in 2019. In the case of epoetin, a reduction of up to $66 \%$ in the originator's price was recorded upon the introduction of the biosimilar [9]. Biosimilar competition will increase substantially and is estimated to create budget savings of approximately $\$$ US160 billion by 2023 .

Truxima and Herzuma, developed by Celltrion Healthcare, are intravenous biosimilars for rituximab (MabThera) and trastuzumab (Herceptin) that have gained approval from the European Medicines Agency (EMA) in 2017 and 2018 , respectively [10,11]. Rituximab, which is a chimeric mouse-human antibody-targeting cluster of differentiation (CD)-20 ubiquitously expressed on the surface of all B cells, is indicated for patients with rheumatoid arthritis (RA), granulomatosis with polyangiitis, microscopic polyangiitis, chronic lymphocytic leukaemia (CLL), and non-Hodgkin's lymphoma (NHL), and the reference product, intravenous MabThera (MabThera IV) received EMA approval in 2009 [12]. Trastuzumab is a monoclonal antibody that inhibits tumour cell proliferation by binding to human epidermal growth factor receptor 2 (HER2) and is indicated in patients with early breast cancer (EBC), metastatic breast cancer, and metastatic gastric cancer [13], having first received EMA approval in 2008 [14]. Both biosimilars are approved for the same range of indications as their reference drugs. As per the summary of product characteristics (SmPC), the quality, safety, and efficacy of Truxima and Herzuma are comparable to those of their reference drugs [10,11], and no impact on safety or efficacy was detected when switching from reference rituximab to biosimilar Truxima [15].

Rituximab and trastuzumab are also available in subcutaneous formulations. The rituximab product, subcutaneous MabThera (MabThera SC), first received EMA approval for all subcutaneous indications in 2014 [16]. The subcutaneous formulation of trastuzumab (Herceptin SC) received EMA approval for all approved intravenous indications in 2013 [13]. Market share data obtained from tracking sales of prescription medicinal products in EU-5 countries (UK, France, Germany, Spain, Italy) indicate that the subcutaneous formulation of Herceptin attained a market volume share ranging from $30 \%$ in Germany to $90 \%$ in Spain [20]. The literature reported that both patients and healthcare professionals (HCPs) preferred subcutaneous over intravenous formulations because of their ease of administration and the shorter absolute administration time of subcutaneous infusions [17]. The shorter administration time associated with subcutaneous formulations of both these molecules has been shown to deliver cost savings for the healthcare system through the lower commitment of staff resources in addition to reduced consumption of consumable materials [21, 22]. Further benefits for increased treatment capacity have also been proposed because of the increased availability of infusion beds. The ability to treat more patients has been identified as a key value driver of subcutaneous products [21, 22]. However, subcutaneous formulations do not entirely keep patients away from intravenous treatments because certain treatment areas and regimens require combination therapy with other intravenous drugs. For example, when chemotherapy such as the R-CVP (rituximab, cyclophosphamide, vincristine sulfate, and prednisone) or R-CHOP (rituximab, cyclophosphamide, doxorubicin, vincristine sulfate, and prednisone) regimens are administered, cyclophosphamide and vincristine are administered intravenously so intravenous administration of rituximab along with these two agents may make sense. The EMA approved the use of pertuzumab in combination with trastuzumab for adjuvant treatment of adults with HER2-positive EBC at high risk of occurrence. Pertuzumab is only available as an intravenous formulation, and Herceptin $\mathrm{SC}$ requires an $\mathrm{HCP}$ to administer the drug according to the SmPC. The administration time is shorter than for the intravenous formulation, but the need for patients to attend a clinic/facility is not entirely eliminated for a subgroup of patients. Furthermore, administration of one complete dose intravenously is preferred before switching a patient to the subcutaneous formulation in order to settle administration reactions, which are very common with rituximab [23]. Any effect on immunogenicity and prospect of interchangeability between these different formulations on patients is yet to be further established $[18,19]$. An economic evaluation is necessary to consider the differences between intravenous and subcutaneous formulations.

A study investigating the budget impact of biosimilar trastuzumab for the treatment of breast cancer and gastric cancer in 28 European countries indicated savings ranging from $€ 0.91$ billion to 2.27 billion over 5 years [24]. Studies involving biosimilar rituximab have also indicated financial savings for healthcare payers upon the replacement of the originator biologic with a biosimilar [25, 26]. Cost savings can be used to recruit more HCPs, thereby reducing the patient's waiting time and contributing to the efficient use of other healthcare resources [27]. A budget impact study analysing the switching of branded rituximab to its biosimilar over a 3-year time horizon in 28 European countries 
predicted that the $€ 570$ million saved may enable the treatment to be extended to around 48,000 new patients [26].

As discussed, biosimilar medicines offer the potential for substantial drug cost savings for the healthcare system. Even in situations where their use may be associated with other additional costs such as administration or consumables (as in the case of a move from subcutaneous to intravenous formulations), the relative magnitude of the drug cost saving compared with the additional costs is an important consideration. The question of whether the drug cost savings would offset the extra administration cost burden and ultimately lead to net cost savings is worthy of investigation given the advent of biosimilars. Furthermore, cost savings would have implications for treatment numbers, as the additional budget could be used to fund the treatment of additional patients, subject to capacity restraints, such as the availability of trained staff, administration facilities, etc.

This study aimed to perform a budget impact analysis of the introduction of the biosimilar products Truxima and Herzuma in EU-5 markets where both the reference intravenous and subcutaneous products are available, from the healthcare payer's perspective.

\section{Methods}

\subsection{Model Structure}

We developed an incidence-based budget impact model (BIM) in Microsoft Excel ${ }^{\circledR} 2016$ to estimate the net cost impact of adopting biosimilar rituximab (Truxima) and biosimilar trastuzumab (Herzuma) in EU-5 markets based on epidemiology data from the literature, market research data on the use of relevant treatments in all indications, and corresponding costs. Two scenarios were modelled:

1. World With: where Truxima and Herzuma were assumed to be funded for the treatment of indicated populations

2. World Without: where Truxima and Herzuma were not funded and all patients were treated with intravenous or subcutaneous reference drugs (i.e. reflecting the market prior to their launch).

The two scenarios were then compared, and the difference in total costs was referred to as the net budget impact of adopting the biosimilars. Cost savings were also expressed in terms of additional patients who could be offered treatment, underlining the potential for biosimilar uptake to expand access. The model assumed that eligible patients received treatment in their incident year and remained on treatment for the full year.
This budget impact analysis was conducted from the payer perspective for the French, German, Italian, Spanish, and UK healthcare systems. This perspective includes direct drug acquisition and administration costs. In the UK, the NHS governs drug payments and estimation of treatment costs; in France and Italy, the national tariff payment system is based on diagnosis-related group (DRG) tariffs; in Germany, the German-diagnostic related grouping tariff system [28] applies; and in Spain, the Spanish drug payment system fully reimburses the provider for the costs incurred purchasing drugs from the manufacturer.

\subsection{Data Sources}

\subsubsection{Population Data}

The indicated populations for MabThera and Herceptin are described in Table 3 in the Electronic Supplementary Material (ESM). Population data were obtained at the national level using the Office for National Statistics databases for the UK [29], the National Institute of Statistics and Economic Studies databases for France [30], the Federal Statistical Office of Germany databases [31], the Italian National Institute of Statistics databases [32], and the National Statistics Institute databases for Spain [33]. For each indicated population, estimates from a pragmatic literature review were used. Adult patients aged $\geq 18$ years were included in all indications except metastatic gastric cancer, where no age stratification was applied. To obtain an estimate for the adult female population, gender stratification was applied for the breast cancer indications of trastuzumab (early and metastatic). National population growth and incidence rates for each indication were assumed to be constant for the time horizon of 5 years.

The incidence and prevalence of the indicated conditions in the EU-5 markets are presented in Table 1.

\subsubsection{Market Volume Share Data and Assumptions}

The market volume share data for the world without Truxima and Herzuma were based on market research using the IQVIA MIDAS analytics platform, which captures sales data of prescription medical products. We assumed that, when both intravenous and subcutaneous products were approved for an indication, market volume share was split between intravenous and subcutaneous formulations. In indications with only one formulation, the entire market volume share for that molecule was assigned to that product. The prescription sales data are not specific to each indication, so the aggregate market volume share was assumed to apply in each indication. Tables 1 and 2 present the market volume share distribution for MabThera and Herceptin (both 
Table 1 Incidence and prevalence for the approved indications across EU-5 countries (UK, France, Germany, Spain, Italy)

\begin{tabular}{|c|c|c|c|c|}
\hline Drug & Indication & Incidence (per 1000 PY) & $\begin{array}{l}\text { Prevalence (proportion of pts } \\
\text { meeting eligibility criteria for } \\
\text { indication as detailed in the } \\
\text { next column) }\end{array}$ & $\begin{array}{l}\text { Pt characteristics/population } \\
\text { considered for prevalence } \\
\text { calculation }\end{array}$ \\
\hline \multirow[t]{5}{*}{ Rituximab (MabThera) } & RA & 0.08 [34]-0.9 [35] & $10[16,23,36]-30 \%[23,37]$ & $\begin{array}{l}\text { Adult pts with severe active RA } \\
\text { with inadequate response to } \\
\text { other DMARDs }\end{array}$ \\
\hline & CLL & $0.045[38]-0.07$ [39] & $45[23,40]-100 \%[23,40]$ & $\begin{array}{l}\text { Adult pts with previously } \\
\text { untreated and relapsed/refrac- } \\
\text { tory CLL (assumption that all } \\
\text { incident cases are untreated) }\end{array}$ \\
\hline & GPA & $0.002[41]-0.029$ [42] & $100 \%[13,23]$ & $\begin{array}{l}\text { Adult pts with severe active } \\
\text { GPA, receiving glucocorti- } \\
\text { coids }\end{array}$ \\
\hline & MPA & $0.001[43]-0.079$ [42] & $100 \%[13,23]$ & $\begin{array}{l}\text { Adult pts with severe active } \\
\text { MPA, receiving glucocorti- } \\
\text { coids }\end{array}$ \\
\hline & $\mathrm{NHL}^{\mathrm{a}}(\mathrm{FL}+\mathrm{DLBCL})$ & $0.16[44,45]-0.24[44,45]$ & $\begin{array}{l}49.9[13,16,23]-100 \%[16, \\
23]\end{array}$ & $\begin{array}{l}\text { Adult pts with stage III-IV FL } \\
\text { in combination with chemo- } \\
\text { therapy or chemo-resistant } \\
\text { Adult pts with CD20-posi- } \\
\text { tive DLBCL in combination } \\
\text { with CHOP }\end{array}$ \\
\hline \multirow[t]{3}{*}{ Trastuzumab (Herceptin) } & EBC & 0.717 [46]-1.482 [47] & $12[48,49]-19 \%[48,50]$ & $\begin{array}{l}\text { Adult females with HER2- } \\
\text { positive breast cancer }\end{array}$ \\
\hline & $\mathrm{MBC}$ & $0.04238[51,52]-0.17[53]$ & $17.5[48]-30 \%[48,54]$ & $\begin{array}{l}\text { Adult females with HER2- } \\
\text { positive breast cancer }\end{array}$ \\
\hline & MGC & $0.08[55,56]-0.211[46]$ & $18[48,54]-25.8 \%[48,57]$ & $\begin{array}{l}\text { Adult pts with MGC whose } \\
\text { tumours have HER2 over- } \\
\text { expression by IHC } 2+\text { and } \\
\text { confirmatory SISH or FISH } \\
\text { results or IHC } 3+\text { result }\end{array}$ \\
\hline
\end{tabular}

$C D$ cluster of differentiation, $C H O P$ cyclophosphamide, doxorubicin, vincristine sulfate, and prednisone, $C L L$ chronic lymphocytic leukaemia, $D L B C L$ diffuse large B-cell lymphoma, DMARD disease-modifying anti-rheumatic drugs, $E B C$ early breast cancer, $F I S H$ fluorescence in situ hybridization, $F L$ follicular lymphoma, GPA granulomatosis with polyangiitis, $H E R 2$ human epidermal growth factor receptor 2 , $I H C$ immune histo-chemistry, $M B C$ metastatic breast cancer, $M G C$ metastatic gastric cancer, $M P A$ microscopic polyangiitis, $N H L$ non-Hodgkin lymphoma, $p t$ patient, $P Y$ patient-years, $R A$ rheumatoid arthritis, $S I S H$ silver-enhanced in situ hybridization

${ }^{a}$ Incidence of ' $N$ ' pts reported by the World Health Organisation International Agency for Research on Cancer was converted to incidence per $1000 \mathrm{PY}$

intravenous and subcutaneous formulations) in the world with and world without Truxima and Herzuma, respectively.

In the base-case model, market volume share was distributed between the reference drugs and biosimilar products. A share forecast based on historical biosimilar uptake trends was made using IQVIA sales data, and, in the base-case analysis, the challenge of displacing the subcutaneous share was acknowledged by imposing a limit on the extent of the subcutaneous share erosion: Subcutaneous share does not decrease by more than $10 \%$ for trastuzumab or $15 \%$ for rituximab from the peak share predicted by the forecasting. This point of maximum decline should be viewed as a plateau that the subcutaneous share will assume when it declines to this point from its peak. In scenario analysis, the rate at which the intravenous biosimilar displaced the subcutaneous reference product was varied in three scenarios, enabling consideration of different uptake levels (details of the market volume share data for the reference drugs and their biosimilar counterpart [base case] are presented in Tables 1 and 2 in the ESM).

\subsubsection{Drug Dosage}

The dosing details for MabThera, Truxima, Herceptin, and Herzuma for all indications included in the model were extracted from the relevant SmPCs. Details of the mean dose and dosing scheme for the reference product are presented in Table 12 in the ESM. 
Table 2 Total net budget impact using Truxima (200 mg pack size) and potential additional patients across EU-5 countries

\begin{tabular}{llllllll}
\hline Country & Cost category & Year 1 & Year 2 & Year 3 & Year 4 & Year 5 & Total \\
\hline UK $^{\mathrm{a}}$ & Net budget impact & $-5,369,808$ & $-10,911,516$ & $-12,224,685$ & $-13,844,871$ & $-14,009,484$ & $-56,360,364$ \\
& Potential additional patients & 661 & 1331 & 1482 & 1667 & 1687 & 6828 \\
France & Net budget impact & $-9,883,397$ & $-14,240,441$ & $-18,808,192$ & $-21,238,051$ & $-22,947,580$ & $-87,117,661$ \\
& Potential additional patients & 1057 & 1512 & 1979 & 2222 & 2393 & 9163 \\
\multirow{2}{*}{ Germany } & Net budget impact & $-20,400,688$ & $-47,544,769$ & $-71,524,019$ & $-82,072,162$ & $-82,318,378$ & $-303,860,016$ \\
& Potential additional patients & 1052 & 2455 & 3689 & 4231 & 4244 & 15,671 \\
Italy & Net budget impact & $-7,802,594$ & $-28,465,250$ & $-35,233,894$ & $-35,121,145$ & $-35,008,758$ & $-141,631,641$ \\
& Potential additional patients & 463 & 1649 & 2028 & 2022 & 2015 & 8177 \\
Spain & Net budget impact & $-653,985$ & $-866,759$ & $-832,140$ & $-767,968$ & $-936,201$ & $-4,057,052$ \\
& Potential additional patients & 47 & 62 & 60 & 55 & 67 & 291 \\
\hline
\end{tabular}

${ }^{\text {a }}$ Currency is GBP $(\mathfrak{E})$ for the UK and euro $(€)$ for the other countries

\subsubsection{Cost Data}

2.2.4.1 Administration Costs In the EU-5 countries, payers typically reimburse providers using DRG payments. These payments often encapsulate administration costs, implying that any cost differences between products with different administration routes are captured. The DRG cost data were identified and used as payer administration costs in the models for France, Germany, Italy, and Spain (for Italy, the Lombardy region was assumed to be representative of the country). However, in the UK, with provider resources such as staff time and consumables ultimately falling into the payer's budget (the central payer), the trade-off between drug cost savings and additional administration costs is relevant. This was the approach followed by previous UK studies that assessed cost differences between intravenous and subcutaneous formulations, which reported cost savings for the healthcare payer based on administration cost savings driven by the shorter administration time of subcutaneous products $[21,22]$. When adopting the UK payer's perspective, administration and resource use costs in the model were included, similar to previous publications reporting intravenous versus subcutaneous costing, i.e. a micro-costing approach that assigned a value to time and resources consumed in their administration [21, 22].

This model included only direct medical costs related to medication (drug acquisition, resource use, and administration costs) incurred by the healthcare payers. The model included 2018 drug acquisition costs for all the countries in the study. Administration costs in the form of the most recently reported DRG tariffs were identified in the countries in which they are employed: $€ 45.70$ in Italy, $€ 383.11$ in France, and $€ 478.32$ in Spain (for both intravenous and subcutaneous formulations). The higher administration cost for France and Spain is potentially attributable to the inclusion of all costs incurred during the medical activity (e.g. nurse, administration, food costs), whereas in Italy the value represents the cost of an administered vial only. For Germany, the values differ according to the administration route: $€ 74.40$ for subcutaneous and $€ 144.61$ for intravenous. In the UK analysis, the healthcare resource use costs were inflated to year 2017 values using the Hospital and Community Health Service index [58]. The monitoring cost was expected to be equivalent between intravenous and subcutaneous formulations so was excluded from the analysis. In the four other European countries, administration costs for MabThera and Herceptin were informed by DRG tariffs. Funding in France was as per the T2A tariff list, and the administration cost data were sourced from the Technical Agency for Information on Hospitalisation. Administration costs for Germany were those reported by Einheitlicher Bewertungsmaßstab and published by the National Association of Statutory Health Insurance Physicians in Germany [59]. For Italy, data sourced from a hospital database for the Lombardy region were assumed to be representative of Italy as a whole, and for Spain, the Spanish healthcare cost database e-Salud was used. All these were based on lump sum DRG tariffs, included all costs incurred during the medical activity (e.g. nurse, administration, food costs) and were distinguished by administration route where reported. The DRG cost was inflated to year 2018 costs using the consumer price index. The details of the administration costs adopted per country are presented in Tables 13-17 in the ESM.

2.2.4.2 Resource Use Costing In the UK, a micro-costing approach for resource use and administration activities was taken to align with local clinical practice. Approaches previously reported by Rule et al. [21] for rituximab and Burcombe et al. [22] for trastuzumab were adopted in the UK. These studies reported the time involved in administering the MabThera and Herceptin IV/SC formulations and enabled calculation of the direct costs incurred in the process (HCP time and consumables). The reported time taken to administer each formulation was multiplied by the unit cost 
of healthcare staff time (i.e. wages), and the cost of consumables involved was then added, in line with the approach followed in these previous studies. See Tables 19 and 20 in the ESM for the specific details of the UK resource use costing adopted. For Germany, costs associated with administration time for MabThera were used as a proxy for Herceptin IV and $\mathrm{SC}$ in the absence of trastuzumab data.

2.2.4.3 Drug Costing The drug cost data for all the comparators were obtained from relevant local databases: the British National Formulary [60] for the UK; the Lauer-Taxe [61] database, which publishes the manufacturer's drug list prices, for Germany; the national formulary, Gazzetta Ufficiale [62], for Italy; the Bot PLUS database [63] developed by the General Pharmaceutical Council for Spain; and the National Union of Health Insurance Funds for France. In the scenario where Truxima and Herzuma were unavailable in the French market, an assessment of pricing landscape indicated that the introduction of the biosimilars typically instigates a $10 \%$ reduction in the price of the reference product and that the biosimilar price must be equal to or lower than the reduced originator price [64]. Hence, we adopted an assumed price reduction of $10 \%$ for the originator and a reduction of $20 \%$ of the initial originator price for the biosimilar. See Table 18 in the ESM for the drug cost data for the originators and biosimilars across the five European countries.

\subsection{Time Horizon}

The base-case analysis presented costs over 5 years, with the flexibility to retrieve the budget impact at each yearly interval. Year 1 represents the first year in which the biosimilars were launched in each country. Herzuma sales data were collected from different time points in 2018 for France, Italy, Spain, and the UK and in 2017 for Germany. Rituximab sales data were collected from various time points in 2017. Post sales of biosimilars, real-world market share data were used up to 2018 to project the market share for the reference drug and the biosimilars for 2019 and onwards.

\subsection{Scenario Analysis}

To capture the uncertainty around the projected market volume share data, scenario analyses were performed. Three scenarios of subcutaneous originator market activity in response to intravenous biosimilar introduction were modelled.

1. Scenario 1: Subcutaneous originator market volume share was assumed to achieve the highest share it was projected to achieve in the base case for the duration of the 5-year time horizon (i.e. a market volume share plateau at the peak for the model duration).

2. Scenario 2: Upon introduction of the intravenous biosimilar, the subcutaneous originator market volume share was assumed to not decrease from the highest point it was projected to reach over the 5 years by more than $20 \%$ (trastuzumab) or $30 \%$ (rituximab). This point of maximum decline should be viewed as a plateau that the subcutaneous share will assume when it declines to this point from its peak.

3. Scenario 3: The IQVIA market uptake projection based on historical biosimilar uptake trends was used, i.e. with no restriction placed on the share erosion of the subcutaneous products. To calculate this, the post-launch market growth of previous biologic biosimilars in similar therapy areas was applied to rituximab and trastuzumab, with assumptions made for the resulting impact on originator market volume shares.

\subsection{Sensitivity Analysis}

The one-way sensitivity analyses (OWSA) were conducted to test the robustness of the base-case results by varying key model parameters by $\pm 20 \%$ in line with standard modelling practice. OWSA results are presented in the form of tornado diagrams showcasing the impact of individual parameter variation on net budget impact. The parameters selected for sensitivity analysis for Truxima were drug cost, average body surface area (BSA) for patients with NHL, average BSA, estimate of CLL incidence, and estimate of RA incidence. For Herzuma, the parameters were drug cost, average weight of female patients, estimate of EBC incidence, average weight of the adult patient, and estimate of metastatic breast cancer incidence.

\section{Results}

\subsection{Base Case}

\subsubsection{Truxima}

The total budget in the world with Truxima was lower than that in the world without in each year of the model; therefore, adoption of Truxima can lead to cost savings as savings from lower drug acquisition costs outweigh any additional administration costs associated with the intravenous formulation, where applicable. In countries with no additional administration costs due to equivalent tariffs between intravenous/subcutaneous products, the lower biosimilar drug costs contribute exclusively to the cost savings. The net budget impact and potential additional patients that could 
be treated with the cost savings were calculated using the $200 \mathrm{mg}$ pack of Truxima and involving patients with all indications and is presented in Table 2 for the five European countries.

Increased cost savings with each successive year translated into increasing numbers of potential additional patients, ranging from 661 in year 1 to 1687 in year 5 for the UK, from 1057 to 2393 for France, from 1052 to 4244 for Germany, from 463 to 2015 in Italy, and from 47 to 67 for Spain (Table 2). Table 3 provides a breakdown of the net budget impact into drug acquisition costs and administration costs. Additional administration costs associated with MabThera SC were observed only for the UK and German patients with NHL (the subcutaneous formulation is only indicated for NHL).

\subsubsection{Herzuma}

The total cost in the world without was less than that in the world with Herzuma, so the adoption of Herzuma indicates a cost saving (savings from lower drug acquisition costs outweigh additional administration costs). In the countries with no additional administration costs due to equivalent tariffs between intravenous/subcutaneous products, the lower biosimilar drug costs contributed exclusively to the cost saving, i.e. no offset was required. The net budget impact and potential additional patients that could be treated with the cost savings (calculated for patients with all Herzuma indications) are presented in Table 4 for the five European countries. This growth in annual saving reflects an increased market share for biosimilars. Increased cost savings with each successive year translates into increasing numbers of potential additional patients, ranging from 101 in year 1 to 267 in year 5 for the UK, from 342 to 461 for France, from
280 to 888 for Germany, from 212 to 885 for Italy, and from 28 to 144 for Spain.

Table 5 presents a breakdown of the net budget impact into drug acquisition and administration costs. Additional administration costs associated with subcutaneous Herzuma was observed only in the UK and Germany.

\subsection{Scenario Analysis}

A comparative summary of the budget impact results in the base case and the three market volume share scenarios for Truxima and Herzuma are provided in Figs. 1 and 2 for the UK (data for the other countries are presented in Figs. 1-8 in the ESM). Across the countries, scenario 3 was consistently associated with the highest budget impact as the biosimilars displaced the subcutaneous formulation without any of the restrictions applied in the other scenarios, facilitating the largest savings for healthcare payers. In Germany, the model results were relatively less sensitive to these market share scenarios, as subcutaneous displacement in the forecasting using IQVIA data did not show a marked decrease from the peak share. Scenario 1 was consistently associated with the lowest cost savings, as the subcutaneous share decrease from the peak forecast was not permitted, constraining the ability of payers to realise savings through switching to intravenous biosimilars.

\subsection{Sensitivity Analysis}

Figures 3 and 4 show the results for the UK analyses (data for other countries are presented in Figs. 9-16 in the ESM). For both the rituximab and the trastuzumab analyses, the most impactful parameter was the drug price of Truxima and Herzuma.

Table 3 Truxima (200 mg pack size) analysis cost categories across EU-5 countries

\begin{tabular}{|c|c|c|c|c|c|c|}
\hline Country & Cost category & Year 1 & Year 2 & Year 3 & Year 4 & Year 5 \\
\hline \multirow[t]{2}{*}{$\mathrm{UK}^{\mathrm{a}}$} & Drug acquisition & $-5,497,555$ & $-11,464,145$ & $-13,275,436$ & $-15,609,130$ & $-15,786,092$ \\
\hline & Administration & 127,747 & 552,629 & $1,050,751$ & $1,764,258$ & $1,776,608$ \\
\hline \multirow[t]{2}{*}{ France } & Drug acquisition & $-9,883,397$ & $-14,240,441$ & $-18,808,192$ & $-21,238,051$ & $-22,947,580$ \\
\hline & Administration & - & - & - & - & - \\
\hline \multirow[t]{2}{*}{ Germany } & Drug acquisition & $-20,400,688$ & $-47,676,808$ & $-71,639,906$ & $-82,272,630$ & $-82,519,448$ \\
\hline & Administration & - & 132,039 & 115,888 & 200,468 & 201,069 \\
\hline \multirow[t]{2}{*}{ Italy } & Drug acquisition & $-7,802,594$ & $-28,465,250$ & $-35,233,894$ & $-35,121,145$ & $-35,008,758$ \\
\hline & Administration & - & - & - & - & - \\
\hline \multirow[t]{2}{*}{ Spain } & Drug acquisition & $-1,230,627$ & $-3,840,583$ & $-6,987,985$ & $-10,190,382$ & $-12,488,483$ \\
\hline & Administration & - & - & - & - & - \\
\hline
\end{tabular}

${ }^{\mathrm{a}}$ Currency is GBP $(\mathfrak{f})$ for the UK and euro $(€)$ for the other countries 
Table 4 Total net budget impact on using Herzuma and potential additional patients across EU-5 countries

\begin{tabular}{|c|c|c|c|c|c|c|c|}
\hline Country & Cost category & Year 1 & Year 2 & Year 3 & Year 4 & Year 5 & Total \\
\hline \multirow[t]{2}{*}{$\mathrm{UK}^{\mathrm{a}}$} & Net budget impact & $-2,204,061$ & $-5,667,692$ & $-5,707,366$ & $-5,747,318$ & $-5,787,549$ & $-25,113,987$ \\
\hline & Potential additional patients & 101 & 261 & 263 & 265 & 267 & 1156 \\
\hline \multirow[t]{2}{*}{ France } & Net budget impact & $-9,493,825$ & $-13,365,503$ & $-13,347,975$ & $-13,070,683$ & $-12,791,606$ & $-62,069,593$ \\
\hline & Potential additional patients & 342 & 482 & 481 & 471 & 461 & 2238 \\
\hline \multirow[t]{2}{*}{ Germany } & Net budget impact & $-13,128,839$ & $-33,041,672$ & $-42,700,738$ & $-42,007,246$ & $-41,309,208$ & $-172,187,702$ \\
\hline & Potential additional patients & 280 & 705 & 914 & 901 & 888 & 3688 \\
\hline \multirow[t]{2}{*}{ Italy } & Net budget impact & $-10,043,946$ & $-29,545,358$ & $-41,678,097$ & $-42,082,565$ & $-41,897,604$ & $-165,247,570$ \\
\hline & Potential additional patients & 212 & 624 & 881 & 889 & 885 & 3492 \\
\hline \multirow[t]{2}{*}{ Spain } & Net budget impact & $-895,575$ & $-3,590,860$ & $-5,552,400$ & $-5,060,370$ & $-4,551,403$ & $-19,650,608$ \\
\hline & Potential additional patients & 28 & 114 & 176 & 160 & 144 & 622 \\
\hline
\end{tabular}

${ }^{\mathrm{a}}$ Currency is GBP $(\mathfrak{f})$ for the UK and euro $(€)$ for the other countries

Table 5 Herzuma analysis cost categories (budget distribution) across EU-5 countries

\begin{tabular}{lllllll}
\hline Country & Cost category & Year 1 & Year 2 & Year 3 & Year 4 & Year 5 \\
\hline UK & Drug acquisition & $-2,418,938$ & $-6,326,132$ & $-6,370,415$ & $-6,415,008$ & $-6,459,913$ \\
\multirow{2}{*}{ France } & Administration & 214,876 & 658,440 & 663,049 & 667,690 & 672,364 \\
& Drug acquisition & $-9,493,825$ & $-13,365,503$ & $-13,347,975$ & $-13,070,683$ & $-12,791,606$ \\
\multirow{2}{*}{ Germany } & Administration & - & - & - & - & - \\
& Drug acquisition & $-13,145,951$ & $-33,101,561$ & $-42,869,881$ & $-42,232,739$ & $-41,591,388$ \\
\multirow{2}{*}{ Italy } & Administration & 17,112 & 59,890 & 169,142 & 225,493 & 282,180 \\
& Drug acquisition & $-10,043,946$ & $-29,545,358$ & $-41,678,097$ & $-42,082,565$ & $-41,897,604$ \\
\multirow{2}{*}{ Spain } & Administration & - & - & - & - & - \\
& Drug acquisition & $-215,671$ & $-2,472,960$ & $-3,051,378$ & $-1,263,152$ & 533,017 \\
& Administration & - & - & - & - & - \\
\hline
\end{tabular}

${ }^{\mathrm{a}}$ Currency is GBP $(\mathfrak{f})$ for the UK and euro $(€)$ for the other countries

Fig. 1 Summary of net budget impact results for Truxima ${ }^{\circledR}$ : base-case and scenario $1-3$ analyses for the UK

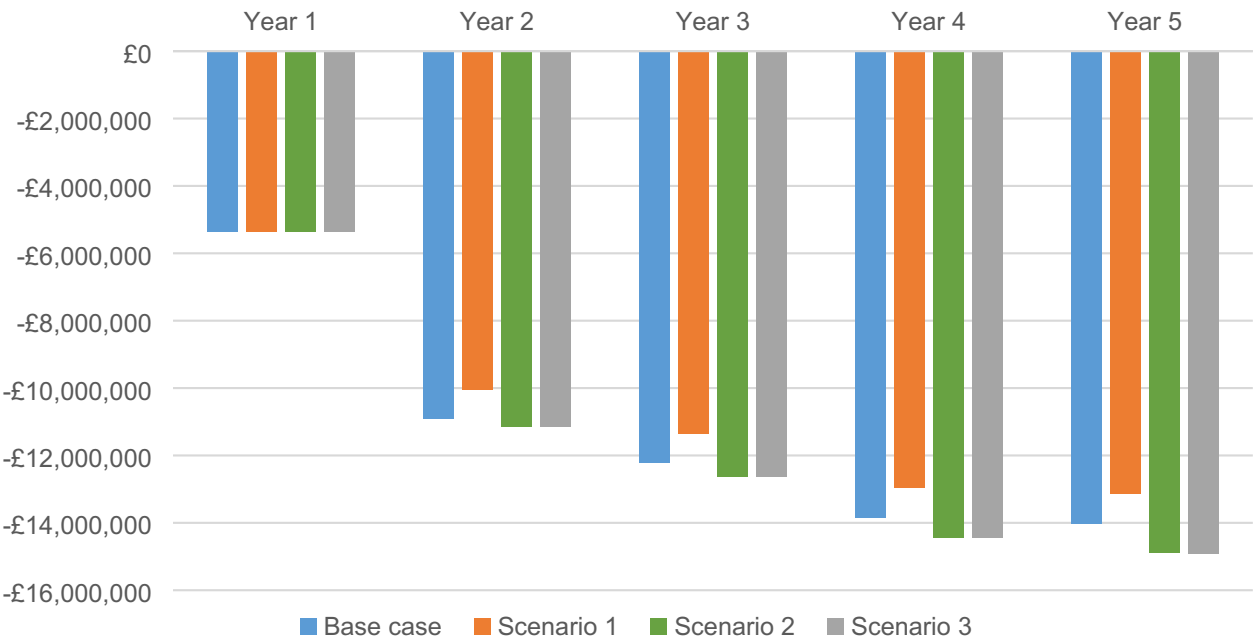


Fig. 2 Summary of net budget impact results for Herzuma ${ }^{\circledR}$ : base-case and scenario 1-3 analyses for the UK

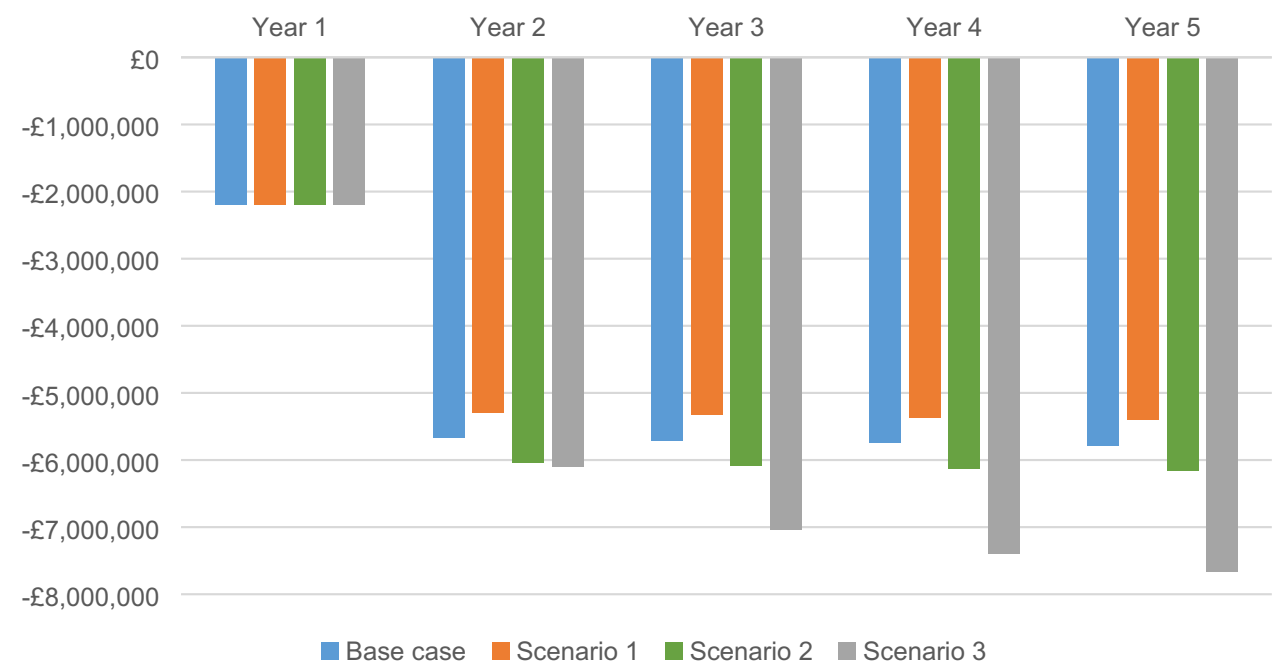

$-200,000,000$

$-150,000,000$

$-100,000,000$

$-50,000,000$

0

$50,000,000$

Drug cost - Truxima

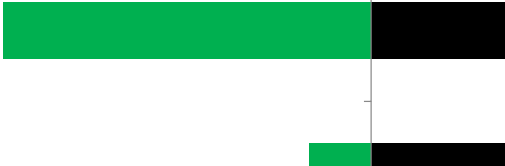

Average BSA of NHL patients

Average BSA

CLL incidence estimate

RA incidence estimate

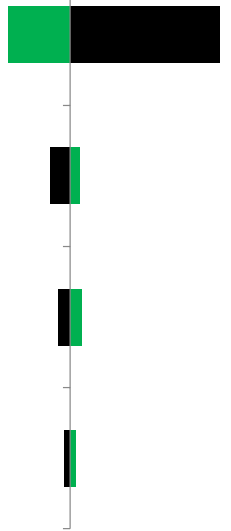

LOW

- $\mathrm{HIGH}$

BSA: body surface area; CLL: chronic lymphocytic leukaemia; NHL: Non-Hodgkin Lymphoma; OWSA: one-way sensitivity analysis; RA: rheumatoid arthritis

Fig. 3 Truxima ${ }^{\circledR}$ OWSA tornado diagram for the UK

\section{Discussion}

This BIM was developed to estimate the costs from the payer's perspective of a market with and without the availability of trastuzumab and rituximab biosimilars in the EU-5 countries in the presence of intravenous and subcutaneous reference products and included the complete indication profile of the reference products over a 5-year time horizon. In particular, our study quantified the trade-off between differences in drug prices and administration costs for subcutaneous and intravenous formulations of trastuzumab and rituximab products in the UK (based on our micro-costing approach) and in Germany (based on different DRG costs for subcutaneous and intravenous formulations). Although DRG 


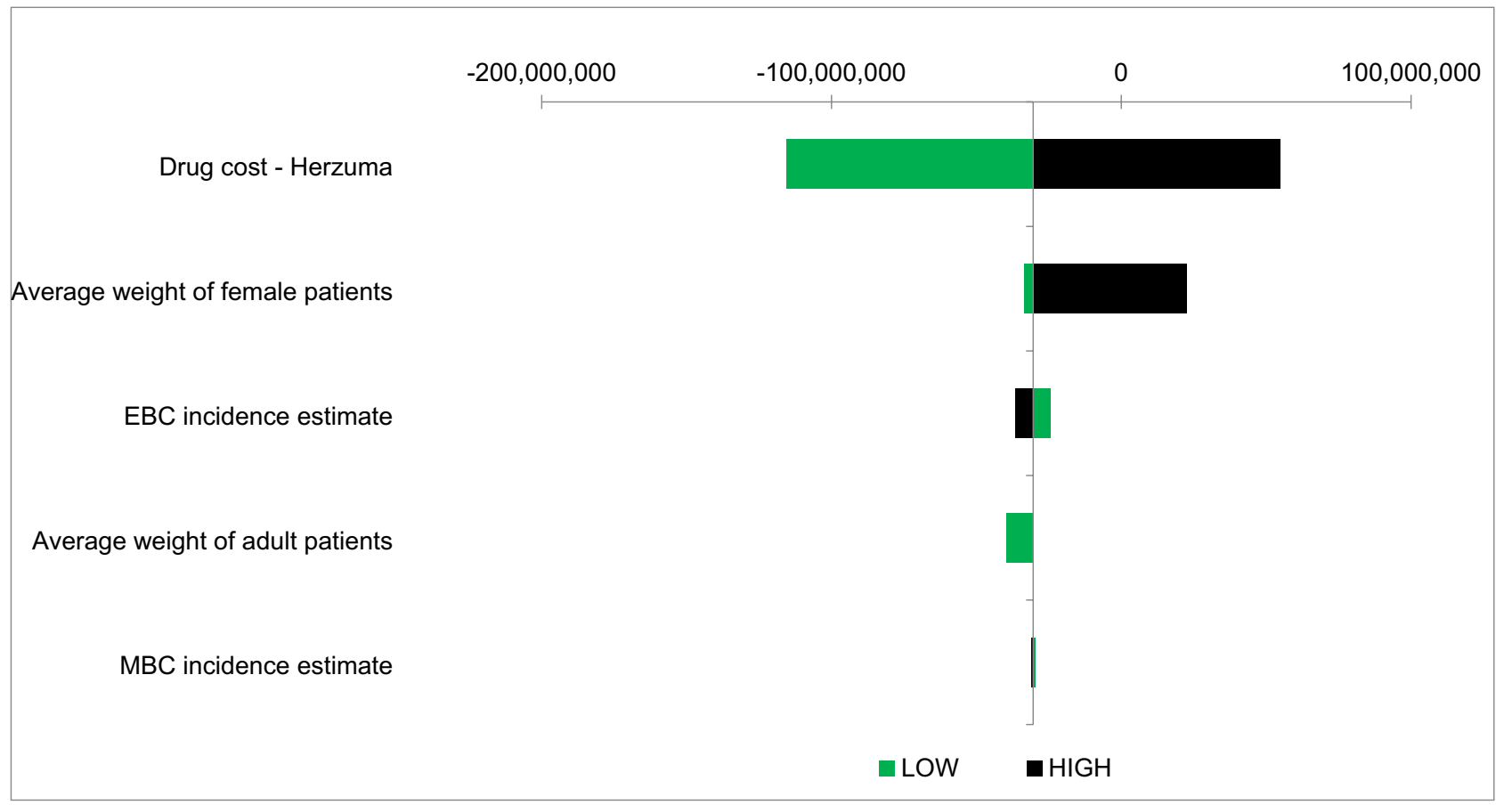

EBC: early breast cancer, MBC: metastatic breast cancer, OWSA: one-way sensitivity analysis

Fig. 4 Herzuma ${ }^{\circledR}$ OWSA tornado diagram for the UK

costs encapsulate administration costs, DRG cost values in France, Italy, and Spain did not differ between subcutaneous and intravenous formulations of trastuzumab and rituximab products. Therefore, our budget impact estimates reflected the impact of drug price differences between intravenous biosimilars and intravenous/subcutaneous reference products for these countries.

\subsection{Key Model Findings}

The base-case results indicated that adoption of the biosimilars Truxima and Herzuma would result in net cost savings. Results from previous studies conducted across European countries analysing the net budget impact of using biosimilars for both MabThera and Herceptin supported the conclusion that replacing the intravenous reference drug with its biosimilar counterpart resulted in cost savings [25, 26, 65]. The present study corroborates that. In these previous studies, the budget savings were attributed exclusively to lower drug acquisition costs for the biosimilars. As the administration route for the biosimilar was the same as that for the reference drugs in these studies, no additional costs were associated with their administration. However, when comparing across a market characterised by both subcutaneous and intravenous products, the potential for additional administration costs with the intravenous formulation must be considered, and this trade-off was investigated in the present study where applicable.
The savings due to the adoption of biosimilar drugs increase the possibility of extending the treatment to additional patients beyond those currently treated. Evidence from the existing literature suggests that the introduction of biosimilars may extend treatment to an additional $7-11 \%$ of patients indicated for MabThera treatment $[22,26,65]$. In this study, the number of potential additional patients ranged from 291 (Spain) to 15,671 (Germany) for rituximab and from 622 (Spain) to 3688 (Germany) for trastuzumab. Where all eligible patients are treated with appropriate treatment, savings could be reinvested in additional services within the healthcare system where delivery is deprived and requires improved patient access. The cost savings in the study were insensitive to plausible variation in the key input parameters. The primary driver was the cost of the biosimilar for all included countries, but no parameter changed the overall result of the budget impact. Scenario analysis, modelling alternative market uptake projections, showed that the estimated budget impact was highest when no erosion restrictions were placed on the subcutaneous product market shares for all countries under consideration, indicating that payers can realise the greatest savings when the possibility of patients receiving the subcutaneous formulation switching to an intravenous biosimilar is maximised.

\subsection{Model Limitations}

The major limitation of this study model was that only the reference products were considered as comparators. This 
could potentially result in an overestimate of the cost savings as other credible comparators could also be less costly than the reference products; therefore, the actual total cost in the world without the biosimilars may be less. The study employed 10-20\% discounts on the list prices of the reference drug and biosimilar. However, observing price trends for reference drugs and biosimilars in other biologics, the actual price discounts are much higher than $20 \%$. Adalimumab is expected to receive a $75 \%$ budget reduction in the UK and infliximab received $70 \%$ discounts in Finland. Thus, 20\% discounts may reflect conservative estimates of budget savings, and actual savings may be higher than or similar to the study results. Confidential discounts and various procurement schemes make it difficult to ascertain the actual drug acquisition cost.

Real-world practice may differ from the described methods and data model because parameters such as annual dosages, staff resource time and associated costs, and patient weight/BSA data were obtained from previously published literature and were not verified by clinicians.

For France, we assumed a 10 and $20 \%$ discount would be applied to the reference products and biosimilar, respectively, upon biosimilar introduction. The National Italian tariff data were not identified, so a large region was assumed to be representative of the whole country.

This study used list prices when calculating drug acquisition costs. List prices in many countries do not reflect the real costs paid by the payers. In particular, because intravenous drugs are procured via different mechanisms in the hospital setting, we assume a significant difference exists between list price and actual transaction price or purchase price. In most cases, the discount is greater for hospital drugs than subcutaneous drugs administered in clinics or retail pharmacies. The magnitude of discount is difficult to estimate in each country and by delivery setting, so this study only incorporated the publicly available list price. Depending on the magnitude of discounts for intravenous and subcutaneous infliximab, possible savings may differ from the result.

\section{Conclusion}

This budget impact analysis emphasised that increased use of intravenous rituximab and trastuzumab biosimilars may result in cost savings from the payer's perspective across the EU-5 countries. Sensitivity analysis indicated that the basecase results were robust. The savings realised from switching patients to biosimilars will help extend the option of treatment to a wider affected population. Scenario analyses established that the drug costs for biosimilar intravenous and subcutaneous product erosion are the most sensitive parameters for cost savings. Furthermore, minor variations in administration costs may not be a barrier to the uptake of intravenous biosimilars. Realising the benefits from biosimilar usage will depend on the price of biosimilars and the capacity of hospitals to distribute a greater volume of intravenous infusions.

\section{Declarations}

Funding Celltrion Healthcare.

Conflict of interest SS is one of the founders of the KU Leuven Fund on Market Analysis of Biologics and Biosimilars following Loss of Exclusivity (MABEL Fund); was involved in a stakeholder roundtable on biologics and biosimilars sponsored by Amgen, Pfizer, and MSD; has participated in advisory board meetings for Pfizer and Amgen; has contributed to studies on biologics and biosimilars for Hospira, Celltrion, Mundipharma, and Pfizer; and has had speaker engagements for Celltrion, Sandoz, and Amgen. MJ and TK have no conflicts of interest that are directly relevant to the content of this article.

Ethics approval Not applicable.

Consent to participate Not applicable.

Consent to publish Not applicable.

Availability of data and material The data that support the findings of this study are available from the corresponding author, TSK, upon reasonable request.

Code availability Not applicable.

Acknowledgement Model programming and medical writing support was provided by IQVIA

Open Access This article is licensed under a Creative Commons Attribution-NonCommercial 4.0 International License, which permits any non-commercial use, sharing, adaptation, distribution and reproduction in any medium or format, as long as you give appropriate credit to the original author(s) and the source, provide a link to the Creative Commons licence, and indicate if changes were made. The images or other third party material in this article are included in the article's Creative Commons licence, unless indicated otherwise in a credit line to the material. If material is not included in the article's Creative Commons licence and your intended use is not permitted by statutory regulation or exceeds the permitted use, you will need to obtain permission directly from the copyright holder. To view a copy of this licence, visit http://creativecommons.org/licenses/by-nc/4.0/.

\section{References}

1. Ageing Europe looking at the lives of older people in the EU: 2019 edition 2019. https://ec.europa.eu/eurostat/documents/32174 94/10166544/KS-02-19\%E2\%80\%91681-EN-N.pdf/c7019 72f-6b4e-b432-57d2-91898ca94893.

2. PW HMA. Europeans of retirement age: chronic diseases and economic activity. https://ec.europa.eu/2012. https://ec.europa.eu/ health//sites/health/files/major_chronic_diseases/docs/rivm_repor t_retirement_en.pdf. 
3. MacNee W, Rabinovich RA, Choudhury G. Ageing and the border between health and disease. Eur Respir J. 2014;44(5):1332.

4. Barbier L, Declerck P, Simoens S, Neven P, Vulto AG, Huys I. The arrival of biosimilar monoclonal antibodies in oncology: clinical studies for trastuzumab biosimilars. Br J Cancer. 2019;121(3):199-210.

5. Per Troein MN, Jyoti P, Kirstie S. The impact of biosimilar competition in Europe 2018. https://quintiles-my.sharepoint.com/ personal/rgoel_in_imshealth_com/Documents/Microsoft $\% 20$ Teams $\% 20$ Chat $\% 20$ Files/IQVIA $\% 20$ Biosimilars $\% 20$ EC $\% 20$ Whitepaper\%20ORB2731F.pdf.

6. Mansell K, Bhimji H, Eurich D, Mansell H. Potential costsavings from the use of the biosimilars filgrastim, infliximab and insulin glargine in Canada: a retrospective analysis. BMC Health Serv Res. 2019;19(1):827.

7. Mulcahy AW, Hlavka JP, Case SR. Biosimilar cost savings in the United States: initial experience and future potential. Rand Health Q. 2018;7(4):3.

8. Matusewicz W, Godman B, Pedersen HB, Fürst J, GulbinovičMack JA, Malmström RE. Improving the managed introduction of new medicines: sharing experiences to aid authorities across Europe. Expert Rev Pharmacoecon Outcomes Res. 2015;15(5):755-8.

9. Iqvia. The impact of biosimilar competition in Europe. 2019. 2019.

10. European Medicines Agency. Truxima 2019. http://www.ema. europa.eu/ema/index.jsp?curl=pages/medicines $/$ human $/$ medic ines/004112/human_med_002077.jsp.

11. European Medicines Agency. Herzuma: EPAR summary for the public 2018 2020. updated 14/02/2020. https://www.ema.europ a.eu/en/medicines/human/EPAR/herzuma.

12. Rituximab EMA. EPAR Mabthera Mediine Overview: European Medicines Agency; 2020. https://www.ema.europa.eu/en/medic ines/human/EPAR/mabthera\#product-information-section.

13. Electronic Medicines Compendium. SmPC Herceptin $600 \mathrm{mg}$ Solution for Injection in Vial 2018. https://www.medicines.org. uk/emc/product/1227/smpc.

14. Agency EM. European Medicines Agency. EPAR Herceptin. Summary for the Public 2020. https://www.ema.europa.eu/en/medic ines/human/EPAR/herceptin.

15. Kim WS, Buske C, Ogura M, Jurczak W, Sancho JM, Zhavrid E, et al. Efficacy, pharmacokinetics, and safety of the biosimilar CT-P10 compared with rituximab in patients with previously untreated advanced-stage follicular lymphoma: a randomised, double-blind, parallel-group, non-inferiority phase 3 trial. Lancet Haematol. 2017;4(8):e362-73.

16. Electronic Medicines Compendium. SmPC MabThera $1400 \mathrm{mg}$ Solution for Subcutaneous Injection 2018. https://www.medicines. org.uk/emc/product/5333/smpc.

17. Lazaro Cebas A, Cortijo Cascajares S, Pablos Bravo S, Del Puy Goyache GM, Gonzalez MG, Perez Cardenas MD, et al. Subcutaneous versus intravenous administration of trastuzumab: preference of HER $2+$ breast cancer patients and financial impact of its use. J BUON. 2017;22(2):3349.

18. Pimentel FF, Morgan G, Tiezzi DG, de Andrade JM. Development of new formulations of biologics: expectations, immunogenicity, and safety for subcutaneous trastuzumab. Pharm Med. 2018;32(5):319-25.

19. Van den Nest M, Glechner A, Gold M, Gartlehner G. The comparative efficacy and risk of harms of the intravenous and subcutaneous formulations of trastuzumab in patients with HER2-positive breast cancer: a rapid review. Syst Rev. 2019;8(1):321.

20. MIDAS $^{\circledR}$ [Internet]. 2018. Available from: Data on file.

21. Rule S, Collins GP, Samanta K. Subcutaneous vs intravenous rituximab in patients with non-Hodgkin lymphoma: a time and motion study in the United Kingdom. J Med Econ. 2014;17(7):459-68.

22. Burcombe RCS, Simcock R, Samanta K, Percival F, Barrett-Lee P. Subcutaneous trastuzumab (Herceptin ${ }^{\circledR}$ ): a UK time and motion study in comparison with intravenous formulation for the treatment of patients with HER2-positive early breast cancer. Adv Breast Cancer Res. 2013;2(4):8.

23. Electronic Medicines Compendium. Electronic Medicines Compendium. SmPC Mabthera $100 \mathrm{mg}$ Concentrate for Solution for Infusion 2018. 2020. https://www.medicines.org.uk/emc/produ $\mathrm{ct} / 3801 / \mathrm{smpc}$

24. Lee S-M, Jung J-H, Suh D, Jung Y-S, Yoo S-L, Kim D-W, et al. Budget impact of switching to biosimilar trastuzumab (CT-P6) for the treatment of breast cancer and gastric cancer in 28 European Countries. BioDrugs. 2019;33(4):423-36.

25. Rognoni C, Bertolani A, Jommi C. Budget impact analysis of rituximab biosimilar in Italy from the hospital and payer perspectives. Glob Reg Health Technol Assess. 2018;2018:2284240318784289.

26. Gulacsi L, Brodszky V, Baji P, Rencz F, Pentek M. The rituximab biosimilar CT-P10 in rheumatology and cancer: a budget impact analysis in 28 European Countries. Adv Ther. 2017;34(5):1128-44.

27. Dutta B, Huys I, Vulto AG, Simoens S. Identifying key benefits in European off-patent biologics and biosimilar markets: It is Not Only About Price! BioDrugs. 2019. https://doi.org/10.1007/s4025 9-019-00395-w.

28. Quentin W, Geissler A, Scheller-Kreinsen D, Busse R. DRG-type hospital payment in Germany: the G-DRG system. Euro Observer. 2010;12

29. Office for National Statistics. Population Estimates for UK, England and Wales, Scotland and Northern Ireland 2016. https://www. ons.gov.uk/peoplepopulationandcommunity/populationandmigrati on/populationestimates/datasets/populationestimatesforukenglan dandwalesscotlandandnorthernireland.

30. Institut national de la statistique et des études économiques. Bilan démographique 2018. 2018. https://www.insee.fr/fr/statistiqu es/1892086? sommaire $=1912926$.

31. Destatis (Statistisches Bundesamt). Bevölkerungsstand 2017. https ://www.destatis.de/DE/Themen/Gesellschaft-Umwelt/Bevoelkeru ng/Bevoelkerungsstand/_inhalt.html.

32. Istituto Nazionale di Statistica. Popolazione residente al $1^{\circ}$ gennaio 2017. http://dati.istat.it/Index.aspx? DataSetCode=DCIS POPRES1\#.

33. Instituto Nacional de Estadistica. Anuario estadistico de Espana. 2018.

34. Carbonell J, Cobo T, Balsa A, Descalzo MA, Carmona L. The incidence of rheumatoid arthritis in Spain: results from a nationwide primary care registry. Rheumatology (Oxford, England). 2008;47(7):1088-92.

35. Benucci M, Cammelli E, Manfredi M, Saviola G, Baiardi P, Mannoni A. Early Rheumatoid Arthritis in Italy: study of incidence based on a two-level strategy in a sub-area of Florence (ScandicciLe Signe). Rheumatology. 2008;28:777-81.

36. National Health Service. Upadacitinib for adults with moderate to severe active rheumatoid arthritis after conventional synthetic disease-modifying anti-rheumatic drugs (DMARDs) or biologic DMARDs failure 2017. http://www.io.nihr.ac.uk/wp-content/uploa ds/2017/12/10453-Upadacitinib-for-Rheumatoid-Arthritis.pdf.

37. Georgi A, Aringer M. Therapiemöglichkeiten nach Nichtansprechen von TNF-Blockern bei rheumatoider Arthritis. 2010.

38. Salvi G, Innocenti I, Autore F, Laurenti L. Chronic lymphocytic leukaemia: census of patients treated in Italian Haematology Units. Medit J Hematol Infect Dis. 2015;7(1):e2015056.

39. Monnereau A, Remontet L, Maynadié M, Binder-Foucard F, Belot A, Troussard X, Bossard N. Estimation nationale de l'incidence des cancers en France entre 1980 et 2012. 2013. 
40. Haute Autorite de Sante. MABTHERA $100 \mathrm{mg}$, solution à diluer pour perfusion B/2 (CIP 560 600-3) MABTHERA $500 \mathrm{mg}$, solution à diluer pour perfusion B/1 (CIP 560 602-6). 2010.

41. Catanoso M, Macchioni P, Boiardi L, Manenti L, Tumiati B, Cavazza A, et al. Epidemiology of granulomatosis with polyangiitis (Wegeners granulomatosis) in Northern Italy: a 15-year population-based study Seminars in arthritis and rheumatism. Amsterdam: Elsevier; 2014.

42. Gonzalez-Gay MA, Garcia-Porrua C, Guerrero J, Rodriguez-Ledo $\mathrm{P}$, Llorca J. The epidemiology of the primary systemic vasculitides in northwest Spain: implications of the Chapel Hill Consensus Conference definitions. Arthritis Rheum. 2003;49(3):388-93.

43. Orpha. Cerca una malattia rara 2014. https://www.orpha.net/conso r/cgi-bin/Disease_Search.php?lng=IT\&data_id=753\&Disease(s)/ group $\% 20$ of $\% 20$ diseases $=$ Microscopic-polyangiitis\&title=Micro scopic-polyangiitis\&search=Disease_Search_Simple.

44. World Health Organisation. Cancer Today 2018. https://gco.iarc. fr/today/home.

45. National Institute for Health and Care Excellence. Rituximab for the treatment of recurrent or refractory stage III or IV follicular non-Hodgkin's lymphoma (Review of TA 37) 2002. https://www. nice.org.uk/guidance/ta137/documents/follicular-lymphoma-ritux imab-final-scope2.

46. Tumori AIR. Cancro del seno 2018. https://www.registri-tumor i.it/cms/contenuto/cancro-del-seno-e-della-tiroide-un-legame-stret to.

47. Institut national du cancer. Quelques chiffres 2012. https://www.ecancer.fr/Patients-et-proches/Les-cancers/Cancer-du-sein/Quelq ues-chiffres.

48. Electronic Medicines Compendium. SmPC Herceptin 150mg Powder for concentrate for solution for infusion 2018. https:// www.medicines.org.uk/emc/product/3856/smpc.

49. Haute Autorite de Sante. trastuzumab. https://www.has-sante .fr/portail/upload/docs/application/pdf/2016-12/herceptin_sein_ precoce_pic_reev_avis2_ct15035.pdf. 2016.

50. Wolff AC, Hammond ME, Schwartz JN, Hagerty KL, Allred DC, Cote RJ, et al. American Society of Clinical Oncology/College of American Pathologists guideline recommendations for human epidermal growth factor receptor 2 testing in breast cancer. Arch Pathol Lab Med. 2007;131(1):18-43.

51. Galceran J, Ameijide A, Carulla M, Mateos A, Quiros JR, Rojas D, et al. Cancer incidence in Spain, 2015. Clin Transl Oncol. 2017;19(7):799-825.
52. Baeyens-Fernández JA, Molina-Portillo E, Pollán M, RodríguezBarranco M, Del Moral R, Arribas-Mir L, et al. Trends in incidence, mortality and survival in women with breast cancer from 1985 to 2012 in Granada, Spain: a population-based study. BMC Cancer. 2018;18(1):781.

53. Robert Koch Institut. Bericht zum Krebsgeschehen in Deutschland 2016. 2016

54. Haute Autorite de Sante. trastuzumab. https://www.has-sante .fr/portail/upload/docs/evamed/CT-14877_HERCEPTIN_PIC_ REEV_Avis2_CT14877.pdf. 2016.

55. Haute Autorite de Sante. trastuzumab. https://www.has-sante.fr/ portail/upload/docs/evamed/CT-15036_HERCEPTIN_Estom ac_PIC_REEV_Avis2_CT15036.pdf. 2016.

56. National Institute for Health and Care Excellence. Cancer registration statistics, England: first release, 2016. 2016. https://www. ons.gov.uk/peoplepopulationandcommunity/healthandsocialcare/ conditionsanddiseases/bulletins/cancerregistrationstatisticsen gland/2016.

57. Bang YJ, Van Cutsem E, Feyereislova A, Chung HC, Shen L, Sawaki A, Lordick F, Ohtsu A, Omuro Y, Satoh T, et al. Trastuzumab in combination with chemotherapy versus chemotherapy alone for treatment of HER2-positive advanced gastric or gastro-oesophageal junction cancer (ToGA): a phase 3, open-label, randomised controlled trial. J Clin Oncol. 2009;27 Suppl:Abstract 4556. 2009.

58. Personal Social Services Research Unit. Unit Costs of Health and Social Care 2017. 2017. https://www.pssru.ac.uk/project-pages/ unit-costs/unit-costs-2017/.

59. Kassenarztliche Bundesvereinigung. 2018. https://www.kbv.de/ html/index.php.

60. British National Formulary. MabThera 2018. https://bnf.nice.org. uk/medicinal-forms/rituximab.html.

61. Lauer-Taxe. LAUER-TAXE ${ }^{\circledR}$ : reliable pharmaceutical information for all drugs and contracts registered in Germany. 2018.

62. Gazzetta ufficiale Mabthera 2017. https://www.gazzettaufficiale.it/ eli/gu/2017/08/09/185/sg/pdf.

63. BotPLUS. Mabthera $100 \mathrm{mg} 2$ Viales $10 \mathrm{ml}$. 2019. https://botpl usweb.portalfarma.com/botplus.aspx.

64. Simon K \& Partners. Payers' price and market access policies supporting a sustainable biosimilar medicines market. 2016.

65. Rencz F, Gulácsi L, Péntek M, Baji P, Brodszky V. Budget impact analysis of biosimilar rituximab (CT-P10) for the treatment of diffuse large B-cell and follicular lymphoma in the $28 \mathrm{EU}$ Member States. Value Health. 2017;20(9):A548. 